Rev. Elet. em Gestão, Educação e Tecnologia Ambiental (e-ISSN: 2236-1170)

\title{
IMPACTOS SOCIOAMBIENTAIS DE HIDRELÉTRICAS E RESERVATÓRIOS NAS BACIAS HIDROGRÁFICAS BRASILEIRAS
}

\author{
Dr. Roberto Naime ${ }^{1}$ \\ ${ }^{1}$ Programa de Pós-Graduação em Qualidade Ambiental, Professor da Engenharia Industrial Química e da Gestão \\ Ambiental - ICET - FEEVALE, RS 239, 2755, Novo Hamburgo, 93.352-000, rnaime@feevale.br
}

\section{RESUMO}

Este trabalho realiza uma abordagem integrada sobre a questão dos impactos ambientais gerais das barragens de terra e grandes reservatórios das bacias hidrográficas. A partir do conceito integrador dos geobiossistemas como unidades capazes de expressar homogeneidades ou realçar diferenciações físicas espaciais e temporais no meio terrestre, sendo unidades territoriais, geográficas ou cartográficas de mesma paisagem, definidas por características estatísticas do meio natural físico, químico ou biológico, hierarquizadas por um mesmo sistema de relações. A partir desta conceituação e partindo de análises bibliográficas ou de relatórios de impactos ambientais, são feitas avaliações sobre os impactos ambientais mais relevantes. É feita também uma discussão sobre os marcos regulatórios de barragens e reservatórios no Brasil e uma sucinta análise da necessidade de governança ambiental permanente na definição dos usos dos recursos hídricos nas bacias hidrográficas.

Palavras-chave: impactos ambientais, reservatórios, bacias hidrográficas

\begin{abstract}
This article develops an integrated approach to the issue of environmental impacts of earth dams and large reservoirs of the hidrographic basins. From the integrative concept of geobiossystemas as units capable of expressing homogeneities or enhance physical differences in spatial and temporal land environment, and territorial units, or geographical maps, the same landscape, defined by the statistical characteristics of the natural physical, chemical or biological, ranked by the same system of relations. From this starting from conceptualization and literature reviews or reports of environmental impacts, assessments are made on the environmental impacts most relevant. We also make a discussion on regulatory frameworks for dams and reservoirs in Brazil and a brief analysis of the need for environmental governance in the definition of permanent uses of water resources in river basins.
\end{abstract}

Keywords: environmental impacts, reservoirs, watershed

\section{INTRODUÇÃO}

Este trabalho faz uma análise descritiva dos impactos ambientais identificados e descritos nas obras de barragens hidrelétricas para geração de energia ou nos barramentos realizados para contenção de águas e formação de reservatórios de usos bastante diversos. 
Rev. Elet. em Gestão, Educação e Tecnologia Ambiental (e-ISSN: 2236-1170)

O Brasil tem uma matriz energética assentada sobre geração de energia através de fontes renováveis ou de baixo impacto ambiental. Mas dentro do contexto das bacias hidrográficas os impactos ambientais gerais que são descritos e os impactos ambientais mais específicos nos meios físico, biológico e antrópico não são desprezíveis. E especificamente dentro do meio antrópico os impactos guardam enormes relações sociológicas e antropológicas ainda não abordadas em toda sua extensão.

\section{METODOLOGIA}

A metodologia utilizada neste trabalho foi a pesquisa bibliográfica em obras de referência na área e em estudos de impacto ambiental e relatórios de impacto ambiental de obras notórias que foi possível acessar. A sistematização procurou classificar os impactos ambientais em campo geral e em dimensões específicas dos meios físico, biológico e antrópico. Nesta última abordagem existe uma enorme interação sociológica e antropológica que ainda necessita maior discussão doutrinária e teórica por parte dos profissionais da área, e que possa estabelecer um campo de relações relevantes com os marcos teóricos destas ciências.

Foi aplicada uma pequena abordagem teórica sobre a necessidade de implantação da governança ambiental permanente nas bacias hidrográficas e não somente na definição e implantação de obras de barramento para fins hidrelétricos ou de irrigação. Foi demonstrado que a ocorrência de conflitos acaba buscando no poder judiciário a solução de impasses que são tipicamente de governança e que se houvesse marcos regulatórios adequados para este exercício permanente, seriam conflitos que teriam solução natural.

\section{GEOBIOSSISTEMAS DAS BARRAGENS E RESERVATÓRIOS}

A interação permanente entre o meio físico e os ecossistemas terrestre e aquático precisa ser analisada através de um enfoque interdisciplinar. As bacias hidrográficas representam a primeira expressão mais visível do meio físico. Resultam da decomposição dos substratos rochosos através de processos de intemperismo.

A bacia hidrográfica é um conceito integrador que precisa ser entendido de forma simples. É uma piscina em escala grande e natural dentro da qual se situam cidades e áreas rurais. E onde tudo que acontecer com uma propriedade rural ou um núcleo urbano afeta os demais elementos da mesma piscina.

As modernas técnicas de avaliação das bacia hidrográficas utilizam as classificações pedológicas e climáticas disponíveis, associando ainda fatores como declividade, cobertura vegetal e ocupação e ação antrópica.

A associação destes elementos e o uso das técnicas de sensoriamento remoto e tratamento digital de imagens de satélite, dentro de um contexto multidisciplinar, permitiu a transferência e a evolução de conceitos. Hoje, é disseminada a concepção do conceito de "paisagem" como expressão do agenciamento dinâmico e superficial dos conjuntos territoriais.

Ou seja, não é mais apenas a bacia hidrográfica que oferece a face mais visível do meio físico, e sim a paisagem integradora do conjunto sistêmico com os demais fatores, a expressão conjunta das interações compreendidas ou ainda difusas.

Este agrupamento, capaz de expressar homogeneidades ou realçar diferenciações físicas 
Rev. Elet. em Gestão, Educação e Tecnologia Ambiental (e-ISSN: 2236-1170)

espaciais e temporais no meio terrestre, origina a conceituação de "geobiossistemas" como unidades territoriais, geográficas ou cartográficas de mesma paisagem, definidas por características estatísticas do meio natural físico, químico ou biológico, hierarquizadas por um mesmo sistema de relações.

Para compreensão e entendimento da evolução das bacias hidrográficas, além da profunda e íntima relação com o clima, é preciso entender as interações com o relevo e a influência dos parâmetros hidrológicos do balanço hídrico (BERMANN, 2004).

Por balanço hídrico se compreende o conjunto de fenômenos posteriores às precipitações pluviométricas. A água que chove sobre uma determinada bacia hidrográfica tem 3 caminhos básicos: o primeiro caminho é sofrer infiltração nos terrenos, que depende das taxas de infiltração, dos materiais constituintes dos solos (materiais arenosos tem elevada permeabilidade e materiais com predomínio de argilas tem baixa permeabilidade).

A segunda alternativa é sofrer "run off", expressão que significa escoamento superficial. Quanto maior for a declividade, maior é o escoamento superficial, e, portanto, menores as infiltrações e menor a decomposição das rochas que origina os solos.

E a terceira é passar pelo processo de evapotranspiração, ou seja evaporação superficial. 0 balanço hídrico é a quantidade de água disponível pela ação das chuvas, menos as águas que infiltram nos terrenos, subtraídas também as águas que sofrem evapotranspiração.

A água disponível para o sistema de drenagem superficial é o material proveniente da chuva que sofre escoamento superficial.

E as taxas maiores ou menores de infiltração, que dependem da quantidade de chuva e do relevo do local, influenciam na formação de maiores ou menores perfis de solo.

Tudo isto ocorre no contexto da bacia hidrográfica. Na ausência deste elemento delimitador do recurso natural, é adotado o conceito de geobiossistema para representar um conjunto de relações responsáveis pela sustentação da flora e da fauna no meio biológico e pelas interações com a agricultura, a pecuária, o armazenamento de água, as obras de infra-estrutura e edificações humanas.

Sem que suas características naturais sejam alteradas, a bacia hidrográfica que é um geobiossistema natural, intuittivo e básico funciona como filtro de purificação das águas superficiais ou freáticas que se infiltram em profundidade e formam os aqüíferos subterrâneos ou águas subterrâneas, armazenadas dentro da rocha.

O manejo agrícola inadequado produz erosão nos solos que constituem uma bacia hidrográfica e resultam nos processos de assoreamento dos recursos hídricos superficiais, aumentando as condições para ocorrência de enchentes e alagamentos.

A disposição inadequada de resíduos perigosos ou não inertes nos solos propicia a degradação progressiva do ecossistema afetado.

O conhecimento da unidade básica de paisagem bacia hidrográfica, geobiossistema natural e intuitivo, é um bom exemplo da multidisciplinariedade dos estudos ambientais. Esta concepção é importante para diversas áreas do conhecimento humano. A bacia hidrográfica é lentamente renovável, sendo determinante na formação das paisagens.

As bacias hidrográficas estão presentes em todas as atividades humanas e seu uso racional, economicamente viável e ambientalmente sustentável exige conhecimento prévio de suas características e limitações.

Todo estudo do meio físico necessita detalhamento das características, aptidões e limitações dos elementos da paisagem. E o elemento integrador por natureza, o geobiossistema natural e intuitivo são as bacias hidrográficas e sua distribuição geográfica e ocorrência. 
Rev. Elet. em Gestão, Educação e Tecnologia Ambiental (e-ISSN: 2236-1170)

\section{ANÁLISE DE IMPACTOS SOCIOAMBIENTAIS DE BARRAGENS E RESERVATÓRIOS}

O Brasil pode se orgulhar e com frequência divulga esta notícia de que é um pais com uma matriz energética voltada para energias chamadas "limpas". De fato, biomassa, energia hidrelétrica e outras constituem uma matriz de geração bastante promissora. No entanto, os reservatórios das hidrelétricas produzem importantes impactos nos principais ecossistemas associados à bacias hidrográficas (CMB, 2004, CBA, 2005)

A função dos reservatórios é muito diversificada. Servem para acumulação e captação de água potável, geração de energia elétrica, reserva de água para agricultura irrigada, produção de biomassa, atividades vinculadas a transportes, recreação e turismo (DAJOZ, 1978, CARVALHO, 2002).

Estes usos múltiplos tem se diversificado e ampliado e criado novas complexidades no funcionamento da paisagem e dos geobiossistemas que emergem do conjunto de relações hierarquizadas entre os meios físico, biológico e antrópico nas diversas regiões do país.

Por meio físico podem ser descritas as rochas, os solos, as águas superficiais e subterrâneas, a geomorfologia e os climas. No meio biológico se ressaltam os elementos de flora e fauna. Enquanto que no meio antrópico se destacam todas as atividades humanas: agricultura, pecuária, indústria, setores terciários, de serviços, infra-estrutura e saneamento dentre outros.

São estas complexas relações que vão definir a nova paisagem dentro das piscinas naturais que são as bacias hidrográficas nas quais estão inseridas as cidades e as propriedades rurais.

O Brasil tem desenvolvidos uma grande capacidade de utilização dos recursos hídricos superficias, mas isto tem sido feito sem qualquer análise da sustentabilidade. Prevalecem os interesses econômicos e sociais, e até mesmo ecológicos, mas com carência de estudos hidrológicos. Alguns destes reservatórios de água tem planejamento inicial e preocupação com inserção regional, mas falta atividade sistêmica e formação de plataformas de dados que possam subsidiar sistemas de desenvolvimentos futuros nestas bacias hidrográficas.

Os reservatórios oscilam desde pequenas barramentos com 1 milhão de $\mathrm{m}^{3}$ até reservatórios de 100 a 200 bilhões de $\mathrm{m}^{3}$ de água.

O padrão de drenagem é muito variado pois em função da natureza geológica ocorrem padrões de drenagens anelas, radiais centrífugos, lagunados, penados e dendríticos. Esta extrema variação morfométrica dificultam a obtenção de dados e o manejo destes reservatórios, que tem múltiplas utilizações desde energia elétrica, regularização de vazões, usos para irrigação, produção de peixes ou crustáceos e usos para lazer, dentre outros.

Não ocorre uma preocupação maior com a fase do sistema hídrico em utilização. Os rios podem ser jovens, em suas nascentes, cujas características são a alta declividade, os vales encaixados e as pequenas áreas inundadas. No Brasil das grandes obras esta fase das drenagens nunca interessou muito porque ela geraria pequenas hidrelétricas, que quer dizer pequenas obras e isto não interessava muito aos empreiteiros. $O$ fato de sistema de drenagem nesta fase produzir os menores impactos ambientais nunca foi motivo suficiente para nada.

A cidade de Barcelona na Espanha é abastecida de energia elétrica com um sistema de pequenas barragens com descarga de fundo que tem tempo de vida útil ilimitado. Descarga de fundo é um sistema mecânico que permite a saída da siltagem acumulada no fundo da barragem devido à precipitação das argilas e siltes suspensos na água, que tendem a decantar em recursos hídricos sem movimento. 
Os rios são maduros na sua fase intermediária e a maioria dos reservatórios brasileiros se localiza nesta fase do curso de água dentro da bacia hidrográfica. Como os vales geralmente são mais abertos e menos encaixados, o tamanho da estrutura de barramento seja de terra, seja de concreto, é maior.

Sempre existem maiores interesses econômicos e melhor relação custo/benefício para o empreendedor. Mas os impactos ambientais são muito maiores. Ocorre maior área de alagamento, maior peso da acumulação de água no reservatório, produzindo pequenos sismos localizados de acomodamento das rochas subjacentes (PETTS, 1999).

Se ocorrer piscicultura ou carcinocultura, ocorre a formação de um sistema tampão que acumula Nitrogênio e Fósforo. Os tributários contribuem com fontes diversificadas de materiais dissolvidos e particulados e a interação co sistema complexo que se forma pode se tornar muito difícil de avaliar e interferir.

As maiores áreas de alagamento são responsáveis por afetar maior quantidade de pessoas a ser deslocada a um custo social relativamente intangível. Atualmente se indeniza a terra e as benfeitorias por um valor e se acredita que está tudo resolvido. Não é assim, ocorre uma total reorientação do uso e ocupação do espaço e as avaliações de impacto ambiental passam muito longe disto. E mesmo para quem fica e não é inundado ocorre uma severa alteração da forma de uso e ocupação do espaço e uma redefinição completa do sistema hierárquico do geobiossistema.

Nas barragens situadas na fase madura do curso de água, como resultante dos grandes reservatórios, ocorrem alterações no microclima que são relevantes. Ocorre alteração na umidade relativa do ar, nas precipitações, no sistema de ventos e tudo mais (ROBERTS, 1990).

Quantidade e frequência de precipitações pluviométricas estabelecem padrões climatológicos diferenciados. Durante precipitações pluviométricas de maior intensidade, aumenta a quantidade de matéria inorgânica em suspensão na água, reduzindo a transparência para infiltração de luz, alterando a produção primária fitoplanctônica e a própria sobrevivência das macrófitas. Com isso podem haver drásticas reduções no parâmetro oxigênio dissolvido, indicador fundamental para toda vida aquática (VIANNA, 1990).

Neste contexto a falta de sincronia entre os eventos introduzem novos mecanismos de alteração nos reservatórios, influindo na composição das comunidades zooplantônicas e fitoplantônicas.

A fase final de um rio é quando ele vai desaguar num oceano ou sistema de lagoas, então as declividades são baixíssimas ou quase nulas e não ocorrem encaixes geográficos que permitam a instalação de barragens que com certeza teriam impactos ambientais ainda maiores. É a chamada fase senil do rio.

Os estudos de impacto ambiental e relatórios de impacto ambiental registram no geral, independente da fase do curso de água e geralmente os barramentos e reservatórios são implantados na fase madura dos rios, descrevem os principais impactos ambientais gerais na bacia hidrográfica, vale dizer no espaço físico da vida de todas as espécies vegetais e animais, áreas rurais e urbanas e meio físico em geral como sendo:

1. Acidificação da água quando não ocorre desmatamento prévio em escala adequada (HYNES, 1979);

2. Eutrofização produzida pela lixiviação de fertilizantes em áreas agricultáveis adjacentes (HARPER, 1992);

3. Deslocamento de populações em escalas variáveis conforme a topologia, mas sempre significando ampla redefinição do sistema hierárquico entre os meios 
Rev. Elet. em Gestão, Educação e Tecnologia Ambiental (e-ISSN: 2236-1170)

físico, biológico e antrópico do local, que é o geobiossistema da bacia hidrográfica (CMB, 2000);

4. Inundação de áreas agricultáveis ou utilizáveis para pecuária ou reflorestamento (HENRY, 1989);

5. Perdas com flora e fauna nativas que são geralmente muito afetadas em fase de enchimento dos reservatórios;

6. Barragens sempre interferem em processos migratórios e reprodutivos da ictiofauna (HENRY, 1989);

7. Com frequência ocorrem alterações hidrológicas a jusante do reservatório, pois em geral a água represada e utilizada a montante passa a se tornar um déficit hídrico a jusante (HENRY, 1989);

8. Após as alterações produzidas pela plena utilização do reservatório, ocorrem alterações relevantes na fauna aquática e terrestre da bacia hidrográfica;

9. Ocorrem também alterações relevantes quanto à dinâmica dos sedimentos, tanto nos canais do rio à montante e à jusante quanto na bacia de acumulação;

10. Sempre são registrados casos de aumento da distribuição geográfica de doenças de veiculação hídrica;

11. Danos ao patrimônio histórico e cultural;

12. Alterações na dinâmica de uso e ocupação dos solos, onde usos tradicionais são alterados e ocorre redefinição do conjunto de relações hierárquicas que materializa o geobiossitema local da bacia hidrográfica;

13. Os grandes reservatórios registram ocorrência de atividades sísmicas devido ao peso da água sobre o substrato rochoso subjacente (VAINER e ARAÚJO, 1992);

14. A degradação ambiental em geral, perda de biodiversidade em vegetação e animais e a maior disseminação de doenças de veiculação hídrica produz um novo quadro de saúde pública local (ZHOURI, 2005);

15. Efeitos sociais intangíveis da relocação indiscriminada de grandes populações, especialmente agrupamentos indígenas, quilombolas ou comunidades tradicionais (ZHOURI, 2005);

16. Incremento de navegação e transporte na bacia de acumulação causando alterações relevantes dentro da bacia hidrográfica;

17. Intensificação de atividade extrativistas no interior da bacia hidrográfica do reservatório;

18. Alterações nas condições físicas e químicas das águas, que altera a qualidade das águas, favorecendo alguns tipos de organismos e prejudicando a outros;

19. Alterações na temperatura da água, oxigenação (oxigênio dissolvido) e pH (ocorrência de acidificações);

20. Outros tipos de eutrofização.

Cada uma destas alterações produz efeitos diretos e indiretos em uma lista que pode se tornar exaustiva. As grandes bacias hidrográficas brasileiras tem sido objeto da implantação de reservatórios em cascata que acabam produzindo efeitos e por consequência impactos ambientais crescentes e cumulativos, que transformam inteiramente as condições biogeofísicas, econômicas e sociais de toda bacia hidrográfica (REZENDE, 2003).

O meio físico pode ser resumido como sendo constituído pelas rochas, solos, águas superficiais, águas subterrâneas, geomorfologia e climas. 
Rev. Elet. em Gestão, Educação e Tecnologia Ambiental (e-ISSN: 2236-1170)

As principais modificações no meio físico geradas pela construção sequencial de reservatórios nas bacias hidrográficas são registradas como sendo:

1. Alterações nos regimes de recarga dos aquíferos subterrâneos em rochas que passam a sofrer maior infiltração, que podem significar alteração do Número de Reynolds e modificações de fluxo entre laminar e turbulento (ABRAMOVITZ, 1996);

2. Alterações no regime hidrológico superficial do próprio rio, devido à regulação do fluxo e do nível de água, alterando os regimes de inundação e tempo de permanência das áreas alagadas, o que se reflete em alterações de flora, fauna e utilização (VAINER et al, 1992);

3. A retenção de fósforo e a exportação de nitrogênio são modificações capazes de gerar eutrofização relevante à jurante do reservatório (HARPER, 1992);

4. Nas áreas da bacia de acumulação ocorrem alterações significativas nos regimes de reprodução de flora e fauna, com grande frequência ocorrem alterações no processo de piracema que é fundamental para a reprodução da ictiofauna;

5. A retenção física de sedimentos à montante do reservatório acentua a capacidade de gerar fenômenos erosivos pelo fluxo de água à jusante do reservatório, sendo que a retenção de sedimentos também interfere nos ciclos biogeoquímicos e na qualidade da água em geral.

Os impactos ambientais específicos do meio biológico descritos nos estudos de impacto ambiental e relatórios de impacto ambiental registrados são como se seguem:

1. Poluição das águas, contaminações e introdução de substâncias tóxicas nos reservatórios pela lixiviação de pesticidas, herbicidas e fungicidas nas plantações existentes no interior da bacia hidrográfica (FREEDMAN, 1995; GREENBERGS, 1992);

2. Introdução de espécies exóticas nos reservatórios, em desequilíbrio com os ecossistemas da bacia hidrográfica;

3. Remoção de mata ciliar em tributários ou no próprio canal de drenagem principal;

4. Incremento desordenado de pesca predatória, por pescadores profissionais ou atividades de lazer;

5. Elevação do material em suspensão na água devido à atividades agrícolas, com efeitos sobre flora e fauna;

6. Uso excessivo e descontrolado de equipamentos de recreação que interferem na fauna aquática;

7. Deterioração das margens por assentamentos urbanos ou rurais não planejados;

8. Drenagem e eventual remoção e destruição de áreas alagadas e ecossistemas específicos (HYNES, 1979);

9. Ocorrência de eutrofização pelos ciclos de Nitrogênio e Fósforo e pela contaminação por lixiviados de fertilizantes (HARPER, 1992);

10. Remoção ou alteração em espécies de relevante importância dentro da cadeia alimentar dos ecossistemas locais da bacia hidrográfica;

11. Desmatamentos em geral e perda da vegetação característica de áreas de inundação (HENRY, 1989); 
Rev. Elet. em Gestão, Educação e Tecnologia Ambiental (e-ISSN: 2236-1170)

12. Modificações ambientais transformando ambientes lóticos em bênticos com alterações drásticas da fauna aquática e do equilíbrio dos ecossistemas dentro da bacia hidrográfica;

13. Implantação de barreira física para migrações sazonais de espécies faunísticos, perturbando o equilíbrio do ecossistema;

14. Preenchimento rápido do reservatório sem a retirada florestal, que quando se decompõe torna $\mathrm{o} \mathrm{pH}$ da água mais baixo e libera na atmosfera grande quantidade de metano;

15. Diminuição do sequestro de carbono pela vegetação inundada, contribuindo para aumentar o efeito estufa.

Da mesma forma, a experiência de trabalhos análogos na área antrópica geram inúmeros questionamentos e infindáveis combinações:

1. Remoção e relocação de populações com vínculos históricos com os processos de uso e ocupação da paisagem (GOLDSMITH, 1984);

2. Perda de plantios perenes e explotações permanentes (JERONYMO, 2007);

3. Modificações de redes de relações e cooperação com quebra de sinergia entre ocupantes de espaço paisagístico;

4. Redefinição do conjunto de relações hierárquicas que define o geobiossistema local da bacia hidrográfica;

5. Perda de benfeitorias, plantações e áreas agricultáveis ou alagadiças com micro-ecossistemas;

6. Quebra de paradigmas existenciais resultantes da rede de relações históricas locais;

7. Impactos variados sobre a rede complexa de semiótica e simbologia que representa a teia histórica local;

8. Implantação de novos paradigmas axiológicos determinados pela nova rede de relações econômicas locais.

A discussão sobre impactos ambientais gerais, físicos, biológicos e antrópicos dos grandes reservatórios das bacias hidrográficas brasileiras deixa claro que são necessárias ações sistêmicas, continuadas e planejadas para abordagem deste assunto que não mais convive com atitudes espontaneístas, exigindo a implantação de padrões de sustentabilidade imediatamente (ZHOURI, 2004).

\section{MARCO REGULATÓRIO DE BARRAGENS E RESERVATÓRIOS NO BRASIL}

A regulamentação das barragens e grandes reservatórios pela primeira é objeto de lei no Brasil. Embora o diploma legal não aborde de forma muito abrangente a questão fundamental da governança socioambiental da água, até mesmo porque este assunto transcende às barragens e invade as questões das bacias hidrográficas e outras.

Como este projeto foi patrocinado fundamentalmente pela área técnica da construção de barragens, ele se denomina Política Nacional de Segurança de Barragens e este é o principal escopo. A lei 12.334/2010 define responsabilidades e atribuições a respeito do cuidado com a 
Rev. Elet. em Gestão, Educação e Tecnologia Ambiental (e-ISSN: 2236-1170)

segurança das barragens brasileiras. Cria também o Sistema Nacional de Informações sobre Segurança de Barragens (SNISB).

Portanto, em vez de lamentar a falta de abrangência para questões que envolvam a governança socioambiental deste bem natural imprescindível como a água, esta lei deve ser saudada como um enorme avanço porque é uma conquista da sociedade brasileira no sentido que vai dar maior segurança a todos quanto ao monitoramento de segurança das barragens.

A lei traz princípios, objetivos e instrumentos que os profissionais, proprietários e órgãos fiscalizadores deverão seguir para conseguir projeção, construção e operação adequada dos barramentos e reservatórios em bacias hidrográficas.

Como toda lei, resulta de uma mobilização que é sempre um processo, e como tal tem que ocorrer e maturar tanto na sociedade quanto na representação política desta sociedade.

A lei busca solucionar zonas de sombreamento de atribuições entre os órgãos, tentando esclarecer as competências de cada instituição de forma que o sistema funcione com eficiência. São definidos os princípios mínimos a sem seguidos pelos empreendedores de barramentos e reservatórios para operação e manutenção com a segurança adequada. As estruturas serão classificadas em função de seu impacto associado nas áreas econômica, social e ambiental. A legislação define claramente as atribuições e responsabilidades de todos os atores destes cenários (BRASIL, 1981, 1998, 2010).

A engenharia brasileira é reconhecida internacionalmente pela capacidade de projetar, construir e operar estes estruturas. Dentre os fatores predominantes na ocorrência de danos nas barragens e reservatórios estão listados deficiências nos estudos geotécnicos, nos próprios projetos de engenharia e na construção. A aprovação desta política é o primeiro movimento no sentido de regularizar, disciplinar, fiscalizar e monitorar a construção e operação de barragens e reservatórios em todo território nacional (OLIVEIRA et al, 1998).

Os índices internacionais considerados toleráveis são de 1 acidente para cada 10.000 barragens enquanto no Brasil ocorre 1:250 barragens por ano. Isto significa que este atraso em desenvolver um sistema de gerenciamento das barragens gera índices de acidentes até 40 vezes maior que o tolerável (OFFE, 1984).

Estudo da agência nacional de águas registra a existência de 8 mil reservatórios artificiais no Brasil, sendo que os estados com maior número de reservatórios são o Rio Grande do Sul e o Ceará por motivos opostos. No Rio Grande do Sul pela elevada disponibilidade hídrica e a existência de uma cultura de irrigação. Enquanto no Ceará existem muitos reservatórios como tentativa de regularizar a carência hídrica e a falta de água até mesmo para uso e consumo das populações (LEROY, 2002).

O empreendedor é o responsável pelo monitoramento e deve exigir documentação comprobatória do comissionamento, uma espécie de validação da estrutura que deve ocorrer durante a obra e antes do fechamento da barragem ou reservatório (MULLER, 1995).

A lei atribui à Agência Nacional de Águas (ANA) a articulação, implantação e responsabilidade pelo Sistema Nacional de Informações sobre Segurança de Barragens (SNISB).

A fiscalização sobre a segurança das barragens caberá ao outorgante do direito de uso do recurso hídrico no local. Existem prazos para elaboração de laudos e cronogramas de implantação de melhorias, mas tudo em relação à segurança. É um grande passo, mas a lacuna sobre governança socioambiental sobre a utilização do recurso hídrico no contexto da bacia hidrográfica ainda merecerá ser contemplado. 
Rev. Elet. em Gestão, Educação e Tecnologia Ambiental (e-ISSN: 2236-1170)

\section{EXERCÍCIO DA GOVERNANÇA AMBIENTAL NAS BARRAGENS E GRANDE RESERVATÓRIOS DAS BACIAS HIDROGRÁFICAS BRASILEIRAS}

Antes de concluirmos que não acontece o exercício da governança ambiental sobre a utilização da água das bacias hidrográficas nas barragens ou reservatórios, é necessário discutir o que seria esta governança. Ela existe de fato e de direito apenas na concessão do uso do recurso hídrico e até a liberação da implantação do projeto.

A expressão governança socioambiental deriva da concepção de governança corporativa, que é o sistema pelo qual as sociedades são dirigidas e monitoradas a partir do relacionamento de acionistas ou cotistas com o conselho de administração, a diretoria executiva, a auditoria independente e o conselho fiscal. As boas práticas de governança corporativa tem a finalidade de aumentar o valor percebido da organização junto à sociedade, facilitando a obtenção de capital e contribuindo para a perenidade da organização (Instituto Brasileiro de Governança Corporativa, 2010).

Num empreendimento, todos os empregados, clientes, fornecedores, credores, governo e acionistas se sentem partes interessadas ("stakeholders") da operação de um empreendimento e devem ter seus interesses legítimos respeitados tanto através do cumprimento da legislação quanto pela adesão voluntária das organizações a práticas ou protocolos que considerem estes interesses.

Num barramento ou reservatório relevante de bacia hidrográfica, as partes interessadas são todos os integrantes desta bacia hidrográfica, sejam usuários deste recurso natural ou não (ZHOURI, 2005)

A governança ambiental mais do que um conceito é uma prática que visa compatibilizar de forma permanente, os interesses de todas as partes na manutenção de um meio ambiente sadio conforme preconiza o artigo 225 da constituição federal: "Todos têm direito ao meio ambiente ecologicamente equilibrado, bem de uso comum do povo e essencial à sadia qualidade de vida, impondo-se ao Poder Público e à coletividade o dever de defendê-lo e preservá-lo para as presentes e futuras gerações". O dispositivo constitucional revela uma transformação radical sobre o modo de implementação da participação no processo de tomada de decisões no Direito ao introduzir a governança ambiental como processo de participação cidadã. É a expressão de uma vontade de participação no processo de produção de decisões complexas, independente de interpretações técnicas, semânticas ou jurisdicionais do que a Constituição entende por ecologicamente equilibrado.

A gestão socioambiental do reservatório em função dos inúmeros fatores de controle do equilíbrio ecológico dos ecossistemas da bacia hidrográfica e considerando as necessidades dos habitantes integrantes deste geobiossistema é uma atividade que embora não exista ainda, certamente existirá e será regulamentada por diploma legal.

Atualmente, a justiça é sempre chamada a intervir e acaba de forma indireta exercendo a governança ambiental, sempre que interesses entram em conflito em bacias hidrográficas. Na falta de normas hipotéticas que prevejam espécies de suporte fático que simulem situações de conflitos normais decorrentes de interesses ambientais diversos, os conflitos se tornam "law cases". E diante da ausência de normas jurídicas que incidam sobre suportes fáticos decorrentes de interesses conflitantes em casos ambientais, acabam se gerando impasses.

Situações que geralmente são muito complexas porque não envolvem interpretações de normas e sim compatibilizações de interesses multifatoriais decorrentes de interações entre uma quantidade enorme de fatores dos meios físico (rochas, solos, águas superficiais, águas 
Rev. Elet. em Gestão, Educação e Tecnologia Ambiental (e-ISSN: 2236-1170)

subterrâneas, geomorfologia, climas, etc), meio biológico (flora, fauna, ecossistemas, biodiversidade, etc) e fatores antrópicos (ecodesign com análise do ciclo de vida de produtos, eficiência energética, otimização do uso de recursos hídricos, tratamentos de água, efluentes ou esgotos, gestão de resíduos sólidos, monitoramentos atmosféricos e responsabilidade socioambiental) dentro do contexto das bacias hidrográficas.

Então tem cabido aos juízes, promotores e demais operadores do direito a função de exercerem o papel de governança ambiental nas bacias hidrográficas e na sociedade como um todo, legitimando e ouvindo todas as partes interessadas e buscando compatibilizações para as situações de conflito, preservando o meio ambiente e os interesses de todas as partes interessadas.

\section{COMENTÁRIOS À SITUAÇÃO DAS BACIAS HIDROGRÁFICAS DO RS}

O Rio Grande do Sul tem aproximadamente 25 bacias hidrográficas. Um recente estudo do governo do estado indica que 14 destas bac ias hidrográficas se encontram em situação precária ou de alta vulnerabilidade quanto à qualidade de água.

Informações do Relatório Anual de Recursos Hídricos, datado de 2006 indicam grandes preocupações com os mananciais gaúchos. O relatório se encontra defasado em termos de tempo, mas a obtenção de informações sistêmicas de monitoramento hidrográfico sempre é problemática. O único trabalho divulgado anterior a este foi de 2002.

Embora a legislação ambiental predisponha a realização de um relatório anual sobre o tema, este dispositivo nem sempre tem sido atendido.

No estado do Rio Grande do Sul estão algumas das bacias hidrográficas mais degradadas do país como as bacias do Rio dos Sinos e do rio Gravataí.

Os maiores impactos são sobre o nível de oxigenação, presença de coliformes fecais ou quantidade de matéria orgânica. A qualidade da água nestes fatores já compromete o consumo da água. E torna mais onerosos e trabalhosos os procedimentos de tratamento de água para distribuição de água potável.

A análise das bacias hidrográficas mostra que competem na degradação ambiental o despejo de esgotos domésticos não tratados e efluentes industriais com tratamento inadequado ou sem tratamento. No interior do estado, em bacias como as dos rios Turvo, Taquari e Pardo são registradas contaminações por agrotóxicos e dejetos de criações intensivas de animas.

Não é só a qualidade da água disponível nas bacias hidrográficas que gera preocupação. 0 fator quantidade de água também preocupa. Em regiões do estado como Fronteira Oeste, região central e na própria região metropolitana de Porto Alegre ocorre déficit na disponibilidade de recursos hídricos em relação às demandas dos meses de verão. Isto leva à necessidade de racionamento ou de uso de água estocada em barragens ou reservatórios (ORTIZ, 2005).

A situação se agrava no verão não apenas devido ao clima mas também à menor disponibilidade de água em função da ampliação do uso agrícola da água em lavouras irrigadas em culturas de verão como o arroz, largamente cultivado no estado.

A média mundial de uso de água para irrgação oscila entre 70 e $75 \%$, mas a média brasileira se situa em $80 \%$, menquanto no Rio Grande do Sul chega a ocorrer a aplicação de $97 \%$ da oferta hídrica em irrigação durante os meses mais quentes, enquanto no restante do ano fica em $92 \%$ em algumas bacias hidrográficas de regiões agrícolas. Em média o consumo humano fica 
Rev. Elet. em Gestão, Educação e Tecnologia Ambiental (e-ISSN: 2236-1170)

com 4,5\% enquanto a dessedentação de animais fica com aproximadamente 2,3 \% e o consumo industrial atinge $1,1 \%$.

O estado do Rio Grande do Sul tem grande tradição em irrigação, mas é evidente que ocorre superutilização, que gera conflitos de uso e que representa a manutenção do uso de tecnologias defasadas que poderiam e deveriam ser aprimoradas.

Estes dados, embora sofram carência de sistematização e continuidade, servem como alerta para que a sociedade como um todo, através dos comitês gestores de bacias hidrográficas debata e normatize o uso das águas superficiais para que todos os interesses sejam contemplados e não ocorram conflitos de uso e ocupação dos solos tendo como motivo de fundo a utilização dos recursos hídricos, quer sejam superficiais, quer sejam subterrâneos.

A quantidade de água disponível em uma bacia hidrográfica é a mesma, quer sejam utilizadas águas superficiais, quer sejam explotadas águas subterrâneas.

A quantidade de água disponível em uma bacia hidrográfica obedece a uma equação simples, chamada de balanço hídrico. É igual a pluviosidade (ou volume de chuvas) numa determinada região, extraídas as perdas com evapotranspiração. A quantidade de água superficial é a que sofre escoamento. $E$ a quantidade de água subterrânea é a que sofre infiltração em aquíferos.

Mas a quantidade de água disponível em uma mesma bacia hidrográfica independe de ser superficial ou subterrânea. A quantidade de água é a mesma.

Por isto a bacia hidrográfica representa o conjunto mais apropriado para representar o geobiossistema regional, lembrando que esta concepção representa um agrupamento, capaz de expressar homogeneidades ou realçar diferenciações físicas espaciais e temporais no meio terrestre, como unidade territorial, geográficas ou cartográficas de mesma paisagem, definidas por características estatísticas do meio natural físico, químico ou biológico, hierarquizadas por um mesmo sistema de relações.

\section{CONCLUSÕES}

A abordagem holística empregada permite compreender a bacia hidrográfica dentro da concepção de geobiossistema básico de interação e integração humana. As pessoas, suas cidades, propriedades rurais, sua civilização enfim ocorre no interior de bacias hidrográficas e este é o elo que une a todos, a dependência orgânica a este recurso hídrico cíclico.

É desnecessário ressaltar o ciclo da água e sua interdependência com as bacias hidrográficas para compreender a dimensão da interrelação que ocorre.

É necessário ter uma visão do conjunto para alterar a concepção de grandes reservatórios ou grandes barragens que não apresentam características de sustentabilidade a médio ou longo prazos, pois ocorre grande siltagem nos reservatórios e não existe a possibilidade de descarga de fundo.

No entanto, conceber, adotar e implantar sistemas de pequenas e médias barragens em fases preferencialmente juvenis dos cursos de água das bacias hidrográficas são atitudes cada vez mais necessárias para uma boa gestão dos recursos hídricos e da geração energética associada.

Por outro lado, esta prática reduz com intensidade todo tipo de impacto ambiental identificado e neste sentido se torna quase uma imposição natural quando se aborda a dimensão ambiental em sua face mais holística. 
Rev. Elet. em Gestão, Educação e Tecnologia Ambiental (e-ISSN: 2236-1170)

\section{REFERÊNCIAS}

ABRAMOVITZ, J. N. Imperiled Waters, impoverished future: the decline of freshwater ecosystems. Massachusetts, Worldwatch, $1996.80 \mathrm{p}$.

BERMANN, C. Repowering hydroelectric utility plants as an environmentally sustainable alternative to increasing energy supply in Brazil. In: BECKER, M. (Ed.) Research Report, Brasília: WWF-Brasil, 2004. VX., 36p.

BRASIL 1981 - Lei no 6.938/81. Dispõe sobre a Política Nacional de Meio Ambiente. BRASIL 1998 - Lei no 9.605/98. Dispõe sobre os crimes ambientais.

BRASIL 2010 - Lei n 12.334/2010. Dispõe sobre responsabilidades e atribuições a respeito do cuidado com a segurança das barragens brasileiras.

CARVALHO, J. F. A construção e desconstrução do sistema elétrico brasileiro. In: BRANCO, A. M. (Org.). Política energética e crise de desenvolvimento: a antevisão de Catullo Branco. São Paulo: Paz e Terra, 2002. p.97-116.

CBA - Companhia Brasileira de Alumínio. Relatório de impacto ambiental: Usina Hidrelétrica Tijuco Alto. São Paulo, 2005. 144p.

CMB - Comissão Mundial de Barragens (WCD-World Commission on Dams). Barragens e desenvolvimento - uma nova estrutura para a tomada de decisão. (Dams and Development: a new framework for decision-making). UK/USA: Earthscan, 2000. 404p.

DAJOZ, R. Ecologia geral. 3. ed. Petrópolis, Vozes, 1978. 472 p.

FREEDMAN, Bill. Enviromental ecology: the ecological effects of pollution, disturbance, and other stresses. San Diego, CA, Academic Press, 1995. 606 p.

GOLDSMITH, E. The social and environmental effects of large dams. Camelford, Wadebridge Ecological Centre, 1984. 3 v.

GREENBERGS, A. E. (ed.) Standard methods for the examination of water and wastewater. Washington, D.C., American Public Health Association, 1992.

Constituição da República Federativa do Brasil.

HARPER, D. Eutrophication of freshwaters: principles, problems and restoration. London, Chapman Hall, 1992. 327 p.

HENRY, H. Environmental science and engineering. Englewood Cliffs, NJ, Prentice-Hall, 1989. 728 p.

HYNES, H. B. N. The ecology of running waters. Liverpool, Liverpool University Press, 1979. $555 \mathrm{p}$. JERONYMO, A. C. J. Deslocamentos de populações ribeirinhas e passivos sociais e econômicos decorrentes de projetos de aproveitamento hidrelétrico: a UHE Tijuco Alto/SP-PR. São Paulo, 2007. Dissertação (Mestrado) - Programa Interunidades de Pós-Graduação em Energia, Universidade de São Paulo.

LEROY, J. P. Prefácio. In: BERMANN, C. Energia no Brasil: para quê? Para quem? - Crise e alternativas para um país sustentável. São Paulo: Livraria da Física, Fase, 2002. p.7-9.

MÜLLER, A. C. Hidrelétricas, meio ambiente e desenvolvimento. São Paulo, Makron, 1995. 412 p. OFFE, C. Legitimação política por decisão majoritária? In: OFFE, C. Problemas estruturais do estado capitalista. Rio de Janeiro: Tempo Brasileiro, 1984. p.314-54.

OLIVEIRA, Antônio Manoel dos Santos \& BRITO, Sérgio Nertan Alves. Geologia de Engenharia. São Paulo. Associação Brasileira de Geologia de Engenharia - ABGE, CNPq e Fapesp, 1.998

ORTIZ, L. S. (Coord.) Energias renováveis sustentáveis: uso e gestão participativa no meio rural. Porto Alegre: Núcleo Amigos da Terra/Brasil, 2005. 64p. 
Resoluções do Conama no. 001/86 e 020/86.

PETTS, J. Handbook of environmental impact assessment. Oxford, Blackwell, 1999.

REZENDE, L. P. Dano moral e licenciamento ambiental de barragens hidrelétricas. Curitiba: Juruá, 2003. 138p.

ROBERTS, L. E. J. Power generation and the environment. Oxford, Oxford University Press, 1990. 207 p. (Science, Technology, and Society Series ; 6)

VAINER, C. B.; ARAÚJO, F. Grandes projetos hidrelétricos e desenvolvimento regional. Rio de Janeiro: Cedi, 1992.

VIANNA, A. (Org.) Hidrelétricas, ecologia e progresso. Rio de Janeiro: Cedi, 1990. p.35-44.

ZHOURI, A. Relatório final do Projeto PIBIC - "Participação popular em processos de licenciamento ambiental: o caso da PCH Aiuruoca", 2004.

ZHOURI, A. et al. Desenvolvimento, sustentabilidade e conflitos socioambientais. In: ZHOURI, A. et al. (Org.) A insustentável leveza da política ambiental. Belo Horizonte: Autêntica, 2005. p.1124.

\section{AGRADECIMENTOS}

Ao Programa de pós-graduação em Qualidade Ambiental da Universidade Feevale pelo suporte a esta investigação. 